\title{
$\mathrm{RGG/WSN}$ 을 위한 분산 저장 부호의 성능 분석
}

정호영*

\section{A Performance Analysis of Distributed Storage Codes for RGG/WSN}

\author{
Ho-Young Cheong*
}

요 약 본 논문에서는 IoT/WSN을 랜덤 기하 그래프를 이용하여 모델링하고 WSN에서 발생되는 데이터를 효율적 으로 저장하기 위해 사용되는 지역 부호의 성능을 고찰하였다.. 노드 수가 $n=100,200$ 인 무선 센서 네트워크를 랜덤 기하 그래프로 모델링하여 분산화된 저장 코드의 복호 성능을 시뮬레이션을 통해 분석하였다. 네트워크의 총 노드 수가 $n=100$ 일 때와 200일 때 복호율 $\eta$ 에 따른 복호 성공률은 노드 수 $n$ 보다는 소스 노드 수 $k$ 값에 따라 좌우됨을 알 수 있었다. 특히 $n$ 값에 관계없이 $\eta \leqq 2.0$ 일 때 복호 성공 확률은 $70 \%$ 를 상회함을 알 수 있었다. 복 호 율 $\eta$ 에 따른 복호 연산 량을 살펴본 바, $\mathrm{BP}$ 복호 방식의 복호 연산 량은 소스 노드 수 $k$ 값이 증가함에 따라 기하급수적으로 증가함을 알 수 있었다. 이는 소스 노드의 수가 증가할수록 LT 부호의 길이가 길어지고 이에 따라 복호 연산량이 크게 증가하는데 원인이 있는 것으로 생각된다.

Abstract In this paper IoT/WSN(Internet of Things/Wireless Sensor Network) has been modeled with a random geometric graph. And a performance of the decentralized code for the efficient storage of data which is generated from WSN has been analyzed. WSN with $n=100$ or 200 has been modeled as a random geometric graph and has been simulated for their performance analysis. When the number of the total nodes of WSN is $\mathrm{n}=100$ or 200 , the successful decoding probability as decoding ratio $\eta$ depends more on the number of source nodes $k$ rather than the number of nodes $n$. Especially, from the simulation results we can see that the successful decoding rate depends greatly on $k$ value than $n$ value and the successful decoding rate was above $70 \%$ when $\eta \leqq 2.0$. We showed that the number of operations of $\mathrm{BP}$ (belief propagation) decoding scheme increased exponentially with $\mathrm{k}$ value from the simulation of the number of operations as a $\eta$. This is probably because the length of the LT code becomes longer as the number of source nodes increases and thus the decoding computation amount increases greatly.

Key Words : Random Walk, Random Geometric Graph, Internet of Things, Decoding Ratio, Erdös-Rè nyi Model

\section{1. 서론}

각 종 센서와 통신 장치를 부착한 수많은 전자 기기들이 거대한 인터넷에 연결되어 동작하는 현
대의 IoT 네트워크 시스템은 기존의 무선 센서 네 트워크(wireless sensor network, WSN)가 진화된 형태로 볼 수 있다. 센서fmf 통해 데이터를 발생시 키기도 하고 발생된 데이터를 다른 지점으로 전달

Funding for this paper was provided by Namseoul university in 2016.

*Corresponding Author : Department of Information and Communication Engineering, Namseoul University (hycheong@nsu.ac.kr)

Received October 14, 2017

Revised October 16, 2017

Accepted October 17, 2017 
하는 전자 단말기를 노드(node)라고 한다. 특히 온 도나 기후 등을 측정하고 화재 등 여러 가지 재난 현상들을 감시하거나 측정하여 데이터를 발생시키 는 작은 규모의 전자 센서 장치들을 소스 노드 (source node)라고 한다. 이들은 대부분 근접하기 가 어렵거나 열악한 환경에 설치되어 있고 에너지, 메모리 용량, 연산 능력, 배터리 수명, 통신 대역폭 등의 자원이 한정되어 있다. 소스노드들에 의해 생 성된 데이터들은 안정된 전원과 풍부한 저장용량 을 가진 데이터 수집 장치(싱크 노드) 등에 전송하 여 저장할 필요가 있다. 그러나 발생되는 데이터 량이 방대하므로 몇 몇 개의 싱크노드로 데이터를 집중시키는 것은 효율적이지 못하므로 네트워크 내에 분산 저장하여 일부 노드들이 유실되는 경우 에도 유실되지 않은 노드들로부터 데이터를 복원 할 수 있도록 해야 한다[1][11]. 수 많은 노드들이 산재한 IoT/WSN에서 발생한 데이터를 분산 저 장하여 처리하는 가장 효율적인 방법으로 파운틴 부호를 이용한 분산 저장 방법이 가장 효율적인 것으로 인정되고 있다[2].

본 논문에서는 IoT/WSN을 랜덤 기하 그래프 (random geometric graph, RGG)를 이용하여 모델 링하고 이를 이용하여 파운틴 부호 기반 분산 저 장 시스템의 부호 성능을 시뮬레이션을 통해 분석 한다.

\section{RGG 랜덤 그래프를 이용한 WSN/loT}

\section{모델링}

\subsection{Erdös-Rènyi 모델과 RGG 모델}

$n$ 개의 노드들을 갖는 무선 센서 네트워크는 데이터를 발생시키는 $k$ 개의 소스 노드들을 포함 한 형태로 볼 수 있으며 이는 수학적으로 랜덤 그 래프(random graph)를 이용하여 모델링할 수 있 다. 1950년대에 처음 제시된 Erdös-Rènyi 랜덤 그 래프에서는 평면상에 $\mathrm{n}$ 개의 노드(vertex라고 함) 들이 균일하고도 랜덤하게 분포되어 있고 노드들 사이가 정해진 확률 $p$ 에 의해 edge 들이 연결되
어 랜덤 그래프를 형성한다[2][3]. 이와 같은 Erdö s-Rènyi 랜덤 그래프를 $G(n, p)$ 로 표시한다. $\operatorname{Erd}$ ös-Rènyi 랜덤 그래프의 가장 큰 장점은 랜덤 그 래프의 특성이 수학적으로 거의 완전하게 설명될 수 있다는 점이며 그동안 이에 대한 연구가 활발 히 이루어져 왔다. 그러나 Erdös-Rènyi 랜덤 그래 프는 실제 네트워크의 특성과는 부합되지 않는 면 이 많아 현대의 복잡한 네트워크를 모델링하는 데 에는 한계가 있다. 예를 들어, 노드와 노드 사이를 연결하는edge 들의 경우 Erdös-Rènyi 랜덤 그래 프에서는 통계적으로 i.i.d. 특성을 갖는 것으로 가 정하고 있으나 현실세계의 네트워크는 크게 다르 다. 특히 이질적인 네트워크들이 서로 연결되어 하 나의 거대한 네트워크를 이루고 있는 인터넷의 특 성을 Erdös-Rènyi 랜덤 그래프를 통해 모델링하는 것은 어렵다. 이러한 단점을 보완할 수 있는 랜덤 그래프 모델이 랜덤 기하 그래프(이하 RGG로 표 시)이며 무선 센서 네트워크의 특성을 수학적으로 모델링하는데 널리 사용되고 있다[3]

$\mathrm{RGG}$ 에서는 노드들이 일정 영역 내에서 임의 의 확률 분포에 따라 랜덤하게 산재하며, 주어진 거리 $r$ 내에 있는 두 노드(이웃 노드라고 함)는 edge로 연결된다. 이때 거리 $\mathrm{r}$ 은 노드

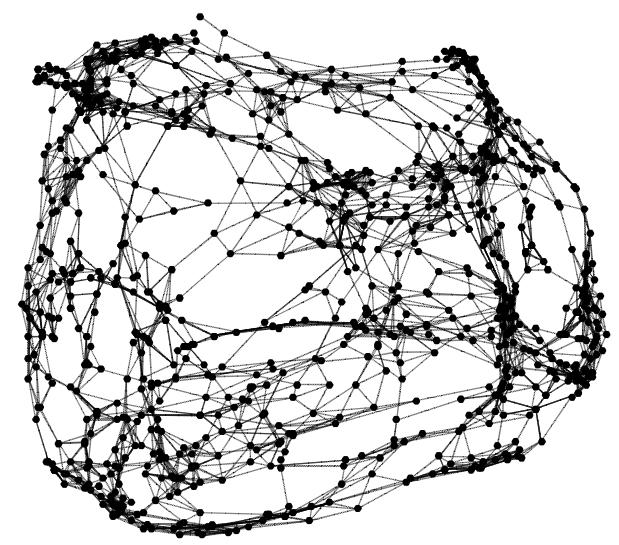

그림 1. 랜덤기하그래프를 이용한 WSN의 모델링 예 $(d=2, n=1000, r=0.05)$

Fig. 1. A WSN Model using RGG $(d=2, n=1000, r=0.05)$ 
들의 통신 범위를 반영한다. $f$ 를 $R^{d}$ 에서 정의 된 확률 밀도 함수라고하고, $X_{1}, X_{2}, \cdots$ 를 동일한 확 률 밀도 $f$ 를 갖고 랜덤하게 산재된 노드들를 나타 내는 i.i.d. 랜덤 변수라고 하면 노드 $X_{n}$ 과 통신 반 경 $r$ 내에서 연결된 edge들이 형성하는 랜덤 그래 프를 랜덤 기하 그래프 $G\left(X_{n}, r\right)$ 이라고 한다. 그림 1 은 $[0,1]$ 사이에서 균일한 확률 분포 $f$ 를 갖는 랜덤 기하 그래프를 나타낸 것인데, 이때 $d=2$ 이 고 노드 수는 $n=1000$ 이며 통신 반경은 $r=0.05$ 이다[3].

$k$ 개의 소스 노드로부터 발생된 $k$ 개의 소스 데이터를 네트워크 내에 저장하기 위해 소스 패킷 은 랜덤 워크(random walk)를 이용하여 전달된다. 각 노드에서 랜덤 워크 패킷을 수신하면 부호화 과정을 수행하여 부호화된 부호 패킷을 저장하고 랜덤 워크 패킷은 다시 이웃 노드 중 하나로 전송 된다[4][6][7].

\section{2 분산 저장을 위한 $\mathrm{LT}$ 부호}

LT 부호(Luby transform code)는 무선 센서 네 트워크에서 데이터 분산 저장에 사용될 수 있는 효율적인 부호이다[5]. $k$ 개의 소스 블록 $\left\{x_{1}, x_{2}, \ldots, x_{k}\right\}$ 에 대해 LT 부호는 다음과 같이 생 성된다. 정수 집합 $\{1,2, \ldots, k\}$ 에 대해 적용되는 확 률 분포 $\Omega$ 를 이용해 $d$ 개의 정수를 랜덤하게 선 택한다. LT 부호에 사용되는 확률 분포 $\Omega$ 는 Ideal Soliton 분포이며 식 (1)과 같다[8][9].

$\Omega_{I}(d)=\left\{\begin{array}{lr}1 / k, & d=1, \\ 1 /[d(d-1)], & d=2,3, \ldots, k\end{array}\right.$

Ideal Soliton 분포를 이용한 LT 부호는 복호화 과정에서 복호 과정이 중단되는 경우가 빈번하게 발생하여 복호화 전체가 실패로 끝나는 경우가 있 으므로 이를 방지하기 위해 실제로는 식 (2),(3)과 같은 Robust Soliton 분포 $\Omega_{d}(d)$ 를 사용하게 된 다. $R=c_{0} \ln (k / \delta) \sqrt{k}$ 라고 하면
$r(d)=\left\{\begin{array}{lrl}R / d k, & d & =1, \ldots, k / R-1, \\ R l n(R / \delta) / k, & d=k / R, \\ 0, & d=k / R+1, \ldots, k\end{array}\right.$

이고, 이때 $c_{0}$ 는 임의의 상수이며 $0<\delta<1$ 의 값을 가진다. 식 (2)를 이용하여 Robust Soliton 분 포 $\Omega_{r}(d)$ 는 식 (3)과 같이 표현할 수 있다.

$$
\Omega_{R}(d)=\frac{\tau(d)+\Omega_{I}(d)}{\sum_{i=1}^{k}\left(\tau(i)+\Omega_{I}(i)\right)}, \quad d=1,2, \ldots, k
$$

(3)

임의의 노드 $u$ 는 센서 노드로부터 출발한 랜덤 워크의 길이가 $C_{1} n \log n$ 보다 작은 패킷을 수신 할 경우 LT 부호화 과정을 수행하고 랜덤하게 선 택된 이웃 노드로 패킷을 전송한다. 한편, 랜덤 워 크의 길이가 $C_{1} n \log n$ 보다 큰 패킷은 버린다. $k$ 개의 소스 패킷들이 모두 $C_{1} n \log n$ 값 보다 큰 값을 가지면 분산 전송과 부호화 과정은 종료된다.

복호화 과정은 데이터 수집기가 $h$ 개의 노드들 로부터 저장 데이터를 수집하여 복호화 과정을 수 행한다. 이때 $\eta=h / k$ 를 복호율(decoding ratio)이 라고 하며 이는 LT 부호에서 복호 오버헤드에 해 당한다. $h$ 개의 부호 데이터로부터 $k$ 개의 소스 데 이터를 LT 부호의 복호 기법인 $\mathrm{BP}$ (belief propagation) 복호 기법을 이용하여 복호하며, $k$ 개 의 소스 데이터가 모두 복호되지 않은 채로 복호 화 과정이 중단되면 다른 노드들로부터 저장된 데 이터를 추가로 전송 받아 복호화 과정을 계속하고 전송 받을 노드들이 없으면 복호화 과정은 실패로 끝나게 된다[10].

각 노드에서 랜덤 워크 패킷을 수신하면 부호화 과정을 수행하여 부호화된 부호 패킷을 저장하고 랜덤 워크 패킷은 다시 이웃 노드 중 하나로 전송 된다. LT 부호의 부호화가 데이터를 발생시키는 소스 노드에서 하는 것이 아니라 데이터를 수신하 는 분산된 각 노드에서 개별적으로 수행한다는 점 이 기존의 LT 부호화와 가장 다른 점이다. 


\section{Decentralized storage 부호}

$k$ 개의 데이터 패킷들을
$x=\left[x_{0}, x_{1}, \ldots, x_{k-1}\right]$ 으로 표시하자. $k$ 개의 데 이터 패킷들을 이용해 식 (4)와 같이 부호 패킷 $y=\left(y_{1}, y_{2}, \ldots\right)$ 을 생성할 수 있다. 부호 패킷 $y_{i}$ 는 $k$ 개의 소스 패킷들로부터 다음과 같이 생성된 다[8]-[10]

$$
y_{i}=x_{r_{0}} \oplus x_{r_{1}} \oplus \ldots \oplus x_{r_{d-1}}
$$

부호화기는 $[0, k]$ 범위에 있는 정수 $d$ 를 확률 분포 $\Omega_{r}(d)$ 를 이용하여 선택한 후 이에 해당하는 $d$ 개의 데이터 패킷들을 식 (4)와 같이 XOR 연산 을 적용하여 부호화 한다. 모든 부호 패킷은 부호 패킷을 생성하기 위해 사용한 $d$ 개의 소스 패킷들 이 XOR 연산에 적용됨을 나타내는 벡터 $b_{i}=\left[b_{i, 0}, b_{i, 1}, \ldots, b_{i, k-1}\right]$ 를 추가하여 송신한다. 이때 소스 패킷 $m_{j}$ 가 부호 패킷 $y_{i}$ 를 생성하는데 사용되었으면 $b_{i, j}=1$ 값을 갖고 사용되지 않았으 면 $b_{i, j}=0$ 의 값을 가진다. 여기에서 $x_{r_{j}}$ 는 $\mathrm{XOR}$ 연산에 사용된 $r_{j}$ 번째 데이터 패킷이다.

\section{1 분산 저장을 위한 부호화 알고리즘}

Decentralized LT 부호화는 WSN에 존재하는 $k$ 개의 소스 노드가 분산되어 있으므로 기존의 LT 부호와 같이 한 곳에서 부호화를 할 수 없다. 따라 서 분산 되어있는 $n$ 개의 노드들이 각자 $k$ 개의 소스 패킷에 대한 부호 패킷을 생성하여 각 각의 노드에서 각 각 생성한 부호 패킷을 따로 저장하 는 것이다. 즉 각 노드들은 $\mathrm{RSD}$ 분포 $\Omega_{d}(d)$ 를 통 해 발생시킨 $d$ 를 이용해각 노드를 방문하는 소스 패킷 중에서 $d$ 개의 소스 패킷을 선정하여 부호화 한 후 각자 분산 저장하게 된다. 부호화 과정을 요 약하면 다음과 같다.

(1) 초기화 단계 : 각 소스 노드 $s(s=1, \ldots, k)$ 는 데이터 $x_{s}$ 에 ID 및 life counter를 포함하고 있는 헤더를 추가한다. 이제 소스 노드는 이웃 노드들 중 한 노드를 랜덤하게 선정하 소스 데이터를 전
송하고, 수신 노드 $u$ 는 부호화할 부호 패킷을 $y_{u}=0$ 으로 초기화한다.

(2) 부호화 단계 : 한 노드 $u$ 에서 확률 분포 $\Omega_{d}(d)$ 에 따라 값 $d$ 를 생성한다. 랜덤 워크 형태로 수신된 데이터 패킷의 수명 카운터 값이 $C_{1} n \log n$ 보다 작으면 노드 $u$ 는 $(d / k)$ 확률 값에 따라 수 신된 데이터 패킷을 선정하여 부호화 한다. 수신 패킷의 카운터 값을 증가시키고 부호화 과정이 끝 나면 다음 이웃 노드로 전송할 수 있도록 대기시 킨다. 만일 수명카운터 값이 $C_{1} n \log n$ 이상이면 모든 노드들을 모두 방문한 것으로 보아 없애고 네트웍 내의 노드들이 모두 $k$ 개의 소스 패킷을 수신하면 부호화 단계를 마친다.

\section{$3.2 \mathrm{BP}$ 복호 알고리즘}

소스 데이터를 복원하고자 하는 데이터 수집 장 치는 $k(1+\epsilon)$ 개의 노드들로부터 각 노드가 가지 고 있는 부호 패킷을 전송 받아 복호하게 된다.

이때 부호 패킷에는 부호화에 사용된 정보 벡터 $\boldsymbol{B}=\left[b_{1}, b_{2}, \cdots, b_{n}\right]^{T}$ 가 같이 포함되어 있으며 이 를 이용해 선형 연립방정식 $B x=y$ 을 구성할 수 있다. 선형 연립방정식 $B x=y$ 로부터 독립이 아닌 방정식들만 제거하면 $(k \times k)$ 행렬 $G$ 와 $(k \times 1) \quad$ 벡터 $Y$ 로 구성되는 연립방정식 $G m=Y$ 를 얻을 수 있다. 이제 연립방정식 $G m=Y$ 의 해를 구하는 과정이 복호화 과정이 다.

$\mathrm{BP}$ 복호 알고리즘에서는 차수가 1 인 행 $G[i]$ 를 탐색하여 행 $G[i]$ 에서 '1'의 열 위치가 $j$ 라고 하면 $m_{j}=y_{i}$ 로 복호한다. 이때 $G[i]$ 는 $G$ 행렬의 $i$ 번째 행을 의미한다. 동시에 $G[i]$ 의 $j$ 번째 열에 있는 모든 ' 1 '들을 ' 0 '으로 바꿈과 동시에 ' 0 '으로 바뀌는 행에 해당하는 부호 패킷 $y_{l}$ 을 $y_{i}$ 와 XOR 연산을 하여 선형 방정식을 갱신한다. $G$ 행렬의 원소가 모두 0이 될 때까지 반복하는데, $G$ 행렬의 원소가 모두 0 이 되면 복호가 성공하여 종료되며 모두 0 이 되기 전에 차수가 1 인 행이 존재하지 않 으면 복호 실패로 중단된다. $G$ 행렬의 원소가 모 
두 0이 되기 전에 복호 실패로 복호화 과정이 중 단되면 이웃 노드들에게 부호 패킷을 추가로 요청 하게 되며 차수 -1 의 부호 벡터를 기다려 복호를 계속 진행한다. 따라서 $\mathrm{BP}$ 복호 알고리즘은 $k$ 값 이 작을 때 오버헤드가 크게 증가하는데 이는 복 호가 성공하기 전에 리플이 자주 비기 때문이다 [8].

\section{4. 시뮬레이션 결과}

본 논문에서는 랜덤 기하 그래프로 모델링된 $n=100,200$ 인 $\mathrm{WSN}$ 에서 분산 저장부호의 복호 성능을 살펴보기 위해 다음과 같이 시뮬레이션을 수행하였다.

우선 WSN은 랜덤 워크 형태로 데이터가 전송 되는 랜덤 기하 그래프로 모델링하였다. 노드 연결 성을 확보하기 위해 통신 반경이 $r=0.2$ 이상의 값을 갖는 랜덤 그래프를 생성하였다. 생성된 랜덤 그래프 상에서 $n$ 개의 노드들에 대해 $10 \%$ 와 $20 \%$ 에 해당하는 $k$ 개의 소스 노드들을 균일하고 랜덤 하게 선택하였다. $\mathrm{RSD}$ 확률 분포 $\Omega_{r}(d)$ 를 구성하 는 파라미터는 $c=0.1$ 과 $\delta=0.01$ 로 하였다.

데이터 수집 장치가 복호를 위해 부호 패킷을 요청한 이웃 노드들이 $h$ 개라고 하면 복호율 (decoding ratio) $\eta$ 는 $\eta=h / k$ 로 계산할 수 있다. $n$ 개의 노드들 중에서 $h$ 개의 노드들을 랜덤하게 선택하여 데이터 요청 노드 집합을 구성한 후 $\mathrm{BP}$ 복호를 적용하여 시뮬레이션을 수행하였다.

그림 2는 네트워크의 총 노드 수가 $n=100$ 일 때와 200일 때 복호율 $\eta$ 에 따른 복호 성공률 $P_{s}$ 를 나타낸 것이다. 그림 2에서 $\mathrm{BP}$ 복호 방식의 복 호 성공 확률은 노드 수 $n$ 보다는 소스 노드 수 $k$ 값에 따라 크게 영향을 받음을 알 수 있다. 특히 $n$ 값에 관계없이 $\eta \leqq 2.0$ 일 때 복호 성공 확률은 $70 \%$ 를 상회함을 알 수 있다.

그림 3은 네트워크의 총 노드 수가 $n=100$ 일 때와 200일 때 복호 율 $\eta$ 에 따른 복호 연산량을 나타낸 것이다. 그림 3 에서 $\mathrm{BP}$ 복호 방식의 복호 연산 량은 소스 노드 수 $k$ 값이 증가함에 따라 기
하급수적으로 증가함을 알 수 있는데, 이는 소스 노드의 수가 증가할수록 LT 부호의 길이가 길어 지고 이에 따라 복호 연산 량이 크게 증가하는데 원인이 있다.

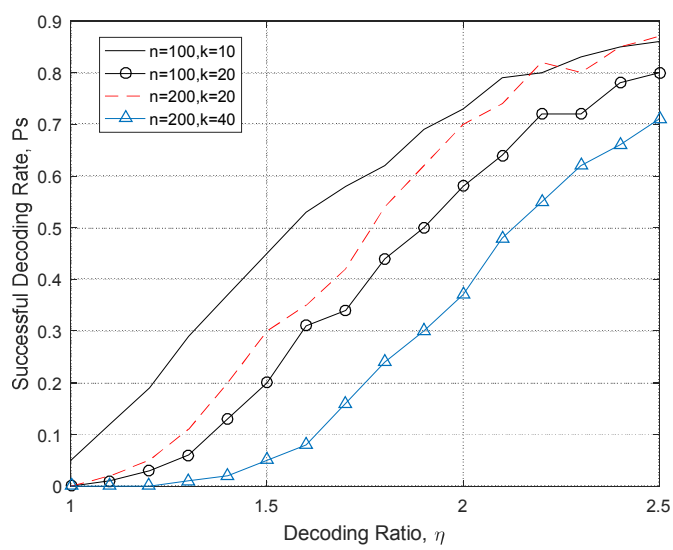

그림 2. 복호율 $\eta$ 에 따른 복호 성공률 $(C \mathrm{l}=1)$

Fig. 2. Successful decoding rate vs. $\eta(C l=1)$

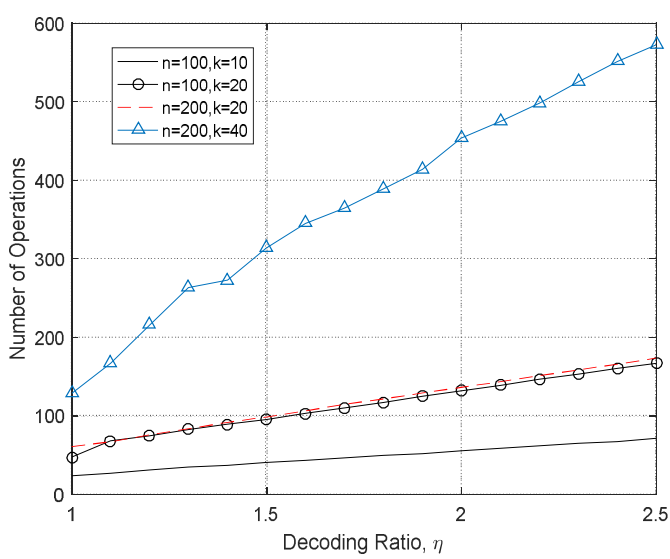

그림 3. 복호율 $\eta$ 에 따른 연산량 $(C \mathrm{l}=1)$

Fig. 3. Number of operations $(C l=1)$

\section{5. 결론}

본 논문에서는 노드 수가 $n=100,200$ 인 무선 센서 네트워크를 랜덤 기하 그래프로 모델링하여 데이터 분산 저장을 위한 분산 부호의 복호 성능 을 시뮬레이션을 통해 분석하였다.

네트워크의 총 노드 수가 $n=100$ 일 때와 200일 
때 복호율 $\eta$ 에 따른 복호 성공률은 노드 수 $n$ 보 다는 소스 노드 수 $k$ 값에 따라 크게 영향을 받음 을 알 수 있었다. 특히 $n$ 값에 관계없이 $\eta \leqq 2.0$ 일 때 기존의 LTCDS 부호의 경우 약 $60 \% 70 \%$ 의 성공률을 보이나[4] $\mathrm{BP}$ 복호기의 복호 성공률은 $70 \%$ 를 상회함을 알 수 있다.

복호율 $\eta$ 에 따른 복호 연산량을 살펴본 바, $\mathrm{BP}$ 복호 방식의 복호 연산량은 소스 노드 수 $k$ 값이 증가함에 따라 기하급수적으로 증가함을 알 수 있 었다. 이는 소스 노드의 수가 증가할수록 LT 부호 의 길이가 길어지고 이에 따라 복호 연산량이 크 게 증가하는데 원인이 있는 것으로 생각된다.

크기가 큰 무선 센서 네트워크의 노드 수는 일 반적으로 수천 개 이상이므로 향 후 $n$ 의 값을 크 게 증가시켜 시뮬레이션을 수행하는 것이 필요하 다. 그림 3 에서 확인한 바와 같이 $n$ 값이 증가하여 이에 따른 $k$ 값이 증가하면 연산 량은 기하급수적 으로 커지므로 복호 연산량을 줄일 수 있 는 연 구도 반드시 필요하다.

\section{REFERENCES}

[1] Dejan Vukobratovič, Ċedomir Stefanovič, Vladimir Cmojevič, Francesco Romano Fantacci, "Rateless Packet Approach for Data Gathering in Wireless Sensor Networks," IEEE Journal on Selected Areas in Communications Volume: 28, Issue: 7, September 2010

[2] Hoyoung Cheong, "On-the-Fly Belief Propagation Decoding of Decentralized Luby Transform Codes for Distributed Storage in a Small-Scale Wireless Sensor Network," Journal of KIIECT, Vol.9 No. 5, Dec. 2016, pp. 503-510.

[3] M. Penrose, Random Geometric Graphs, New York: Oxford University Press, 2003.

[4] Zhenning Kong, Salah A. Aly, Emina Soljanin, “ Decentralized Coding Algorithms for Distributed Storage in Wireless Sensor Networks," IEEE Journal on Selected Areas in Communications, Volume: 28, Issue: 2, February 2010.

[5] A. Kamra, V. Misra, J. Feldman, and D. Rubenstein, "Growth codes: Maximizing sensor network data persistence," in Proc of ACM Sigcom' 06, Pisa, Italy, September, 2006.

[6] Samira Chouikhi, Inès El Korbia, Yacine Ghamri-Doudanec, Leila Azouz Saidane, "A Survey on Fault Tolerance in Small and Large Scale Wireless Sensor Networks, " Computer Communications, Volume 69, 15 September 2015, pp. 22 37.

[7] C. Avin and G. Ercal, "On the cover time of random geometric graphs," in Proc. 32nd International Colloquium of Automata, Languages and Programming (ICALP'05), Lisboa, Portugal, pp. 677 689, July, 2005.

[8] M. Luby, "LT Codes," Proc. of the 43rd Annual IEEE Symp. on Foundations of Comp. Sc., pp 271-280, Vancouver, Canada, November 2002

[9] Valerio Bioglio, Marco Grangetto, Rossano Gaeta, Matteo Sereno, "On the fly Gaussian Elimination for LT Codes," IEEE Communications Letters, Volume: 13, Issue: 12, December 2009, pp 935-955.

[10] Hoyoung Cheong,"An Improved Belief Propagation Decoding for LT Codes,"Journal of KIIECT, Vol.7 No. 4, Dec. 2014, pp. 223 228.[

11] Yoo, Jinho, Choi, Sung-Gi,"Energy Efficient Routing Protocol for Mobile Wireless Sensor Networks,"Journal of KIIECT, Vol.8 No. 5, Dec. 2015, pp 405-411. 


\section{저자약력}

정 호 영(Ho-Young Cheong)

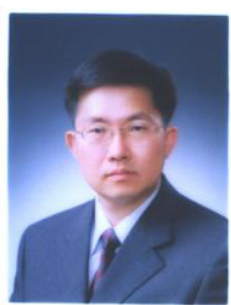

- 1987년 8월 : 연세대학교 대학 원 전자공학과 (공학석사)

- 1995년 2월 : 연세대학교 대학

원 전자공학과 (공학박사)

- 1995년 4월 현재 : 남서울대 학교 정보통신공학과 교수

<관심분야>

채널부호, 분산 저장 부호, 무선 센서 네트워크 